\title{
JOHN RAWLS AND THE CONFLICT BETWEEN RIGHT AND GOOD
}

JOHN MCNAUGHTON

Conduct is complex. It is so complex that attempts to reduce it intellectually to a single principle have failed. We have already noted two leading considerations which cut across each other: ends which are judged to satisfy desire, and the claims of right and duty which inhibit desire.

As John Dewey indicates here, the history of ethics represents, in one sense, a struggle between those who emphasize the role of ends and desires in human conduct (the Good) and those who stress the rights and duties that can be said to "inhibit" desires (the Right). For the most part, the battle lines have been drawn quite clearly, with each side taking careful aim at the other, firing salvos of well-rehearsed arguments as they stand behind a mail of time-honored logical armor. These timeless disputes have carried on to the present day under such guises as natural vs. positive law, teleological or naturalistic ethics vs. deontological ethics, etc. Rarely, however, has anyone come along and attempted to bridge the gap between the two divergent schools of ethical thought. In fact, one might ask (as we shall later in this paper) whether, given the nature of the disputants and the initial premises of their arguments, a truce is even possible between the two warring factions without the total subsumption of one view under the other. More precisely, is a synthesis possible between "rightoriented" and "good-oriented" systems of ethics? Or are they destined to remain forever apart?

Into this ethical breach steps John Rawls, whose book, A Theory of Justice, is undoubtedly one of the major works of ethics in this century. What makes his 
work unique is its comprehensive nature, the attempt to cover all bases in the quest for a meaningful sense of justice. He is not content to remain strictly within one ethical tradition or other, but seeks a view of justice that will take into account the best aspects of all previous theories of justice. He borrows the ideals of personal growth from Aristotle (via his socalled Aristotelian Principle), incorporates the political savvy of Locke, Rousseau, and Hobbes, the socalled contract theorists, and admires (and ultimately endorses) the strict sense of "moral autonomy" that is Kant's contribution to ethics. Furthermore, he attempts to integrate these classical doctrines with some of the "hard" data of the contemporary social sciences.

But whereas traditional systems of ethics have tilted to one side or the other, Rawls seeks a theory of justice that has a strict, "analytical" coherence, but at the same time possesses a solid foundation in the concrete, "synthetic" world of observed human behavior. That is, in terms of the classical dispute mentioned above, he seeks a view of justice that combines the advantages of both good-oriented and right-oriented systems (or to use his terms, a "congruence" between "justice as fairness" and "goodness as rationality"). Thus in Rawls's own words, "what is to be established is that it is rational for those in a well-ordered society to affirm their ${ }^{\text {sense }}$ of justice as regulative of their plan of life." 2 or to put it another way. Rawls wants to show that "the desire to act justly and the desire to express our nature as free moral persons turn out ${ }_{3}$ to specify what is practically speaking the same desire

Does Rawls succeed in this endeavor? Or, perhaps more to the point, can he succeed, i.e.. is such a synthesis or "congruence" between the Right and the Good even possible, given the traditional definitions of these terms? It is to these questions, then, that our paper is addressed. That is, using Rawls as a foil, as an example of one who tries to incorporate or: synthesize the best of both competing approaches, we examine the relative merits of a "right-oriented" or deontological system of justice and a "good-oriented" or naturalistic view. We do so, first, by providing a loose sketch or outline of the two competing views and, second, by briefly examining Rawls's attempt in Part Three of $\underline{A}$ Theory of Justice to contrast the Right and the cood in relation to his own theory. Here we find that despite his professed desire to provide a theory of justice wherein the Right and the Good are somehow 
congruent, he nonetheless tilts ultimately in the direction of the Right, or the deontological, and thus belies his earlier claim for congruence. Finally. Rawls aside, we ask once again, is such a synthesis between Right and Good even possible? or are the notions of Right and Good, as they are traditionally defined, mutually exclusive and, as such, incapable of being joined together on an equal footing? If so, does this render fruitless all attempts such as Rawls's to codify justice in a fair, humane way? or perhaps is the problem not in the actual striving for a coherent system of justice, but in the way the ground rules of the "game" have traditionally been set up? That is, does the traditional terminology of ethics (right vs. good, is vs. ought, etc.) even allow of a solution to such problems, or does it stand as an obstacle in the path to any solution? In this sense, the very strength of Rawls's theory (its comprehensive approach to the subject-matter, the ability to combine the various terminologies and views of widely divergent systems of ethics, and its deep, historical background) may turn out to be its very weakness.

On the formal level, we can approach justice in either of two ways: (1) as an external, formal. "universal," objective quality which can be derived through strict, deductive reasoning and in accordance with whose principles certain laws, norms, or regulations can be prescribed; or (2) as a more naturalistic phenomenon, arrived at through observation or description of basic human interrelationships on both the personal and societal levels.

(1) The first approach to justice is characterized in formal ethics as that of deontology. Briefly sketched, deontology is a nonnatural ethics which emplasizes the performance of duty and the primacy of "right" in an ethical system. On this view some acts are morally obligatory regardless of the consequences they entail, since thay are derived from the overriding concept of Right. Consequently, it is our ethical duty to act always in accordance with this Right. Right is sui generis and can never be reduced to a good or to a teleological theory (Rawls himself emphasizes the latter point quite strongly). The basic mode of reasoning in a deontological system is deductive, i.e.. the values of acts and institutions can be directly related to the principles of Right which exist prior to, and independently of, experience. classically, of course, the major proponent of the deontological approach is Immanuel Kant, who saw ethics as a process of the deductive, rational, and inteljectual 
recognition of an abstract truth (the Right). Rawls's obvious infatuation with Kant needs no comment here, but what is interesting to note is the great deal of attention that Rawls pays to such contemporary deontologists such as Ross, Prichard, and Broad (for example $W$. D. Ross receives eight references in $A$ Theory of Justice, more than just about any other contemporary ethician; more even than Locke or Rousseau!).

(2) The second approach to justice is what might loosely be called the naturalistic approach. Here, more attention is paid to man's cultural endowment and to the descriptive facts of psychology, sociology, economics, science, etc. Unlike deontology, the acts in a naturalistic ethics can be evaluated in terms of the consequences they effect. In this case the principles of justice are always subject to revision, depending on the given ethical situation. Here, ethical systems can arise out of need and social cooperation. the type of reasoning is more "inductive" (i.e., rules, etc. are based on knowledge of general synthetic facts) and is more apt to be based on convention or agreement. The best historical example of this approach to ethics is contained in the works of the utilitarians, who argue that justice presupposes a prior awareness of substantive good, one that pertains to concrete, everyday interaction with the surrounding personal and social environment--namely, the Aristotelian awareness that all persons are always and continually involved in the pursuit of a concrete end, happiness, or pleasure. The American naturalist philosophers, especially Dewey, might also serve as an example of practitioners of this type of ethics.

Having roughly sketched these two basic approaches to justice, we can now perhaps see Rawls's quandary: he wants to incorporate elements of both approaches into his theory. But, as we have already noted, is it really possible to construct a theory of justice based on a synthesis of such seemingly divergent ethical modes? To a large degree, Rawls seems to be successful in this attempt. Nonetheless, it appears that at certain crucial points in his theory he is compelled to force his hand in one direction or other, and in so doing must sacrifice some of the benefits that might accrue from the successful conjunction of the two systems of ethics.

Accordingly, it appears that despite the many compelling arguments presented in the latter part of $\underline{A}$ Theory of Justice with regard to the Good, Rawls 
nevertheless comes down hard on the side of the Right. He wants, ultimately, to show that the principles of justice have such a binding force that all life-plans and plans for the use and distribution of goods must be made in accordnace with them. The clearest expression by Rawls of the contrast and, ultimately, the priority of Right in relation to the cood can be found in section 68 of A Theory of Justice ("The Right and the Good Contrasted"). Therefore we will comment briefly on this section.

First of all, it is interesting to note that this section appears square in the middle of Rawls's rather "naturalistic" explication of the notion of the Good in part Three. In this chapter ("Goodness as Rationality") appear descriptions of such naturalistic phenomena as human life-plans, shame, self-respect, excellence, and deliberation. We label Rawls's approach to these phenomena as naturalistic since, when discussing them, we do not need to make any recourse to absolute, pre-established, formal standards in order to make any sense out of them; i.e.. in this case we are discussing particular human acts and tendencies which arise in particular situations, and whose ethical effects can be judged and evaluated. Thus it appears that in placing this section on the contrast between the right and the good at the end of the chapter on Goodness as Rationality ("lexical ordering," to borrow Rawls's phrase), Rawls is attempting to warn us not to get so caught up in his naturalistic forays that we forget the proper priorities painstakingly deduced in the first part of the book, i.e., the priority of the virtue of justice in human affairs and the priority of right over good. Consequently, even in the most descriptive, naturalistic sections of the book, Rawls's leanings toward the deontological view of justice are luminously evident and the seeming inconsistency of trying to synthesize naturalism and deontology is made most clear.

Section 68, then, is a key section insofar as through its recapitulation of the principles of Right ("justice as fairness") presented earlier in the theory, it attempts to provide the glue by which his theoy of goodness can hold together. The aim of this section is to convince us that under Rawls's principles of justice we stand to lose very little in the way of freedoms and opportunities that we now possess. Furthermore, Rawls empliasizes the importance of diversity in individual life-plans and goods. As a inatter of fact, Rawls contends, our 1 ife-plans and individual ains are more enhanced, since the principles 
of justice as fairness insure the "moral worth" of those plans. He further enphasizes that "there is no urgency to reach a publically accepted judgment as to what is the good of particular individuals." Thus individuals, in the pursuit of their personal goals, need not fear that the binding consensus of the principles of justice will extend downward, as it were, and quash all self-expression. Here, "persons are left to determine their good, 5 the views of others being counted as merely advisory." 5 Rawls even goes further. in the spirit of "goodness as rationality," and argues that it is not only desirable but "rational for members of a well-ordered society to want their plans to be different," since recognition of a diverse range of good in life-plans encourages individual self-respect. that highest of all Rawlsian virtues.

Furthermore, the strictures on knowledge (the "veil of ignorance") which are in effect in the original position and in the principles of justice do not apply once the veil is lifted. Thus, in the discussion and evaluation of individual good, the full range of particular facts of human knowledge is allowed into play. Individual life-plans are to be adjusted to particular situations: "a rational plan of life takes into account our special abilities, interests, and circumstances, and therefore it quite properly depends upon our social position and natural assets."

Rawls here makes a very convincing appeal for the importance of individual 1 ife-plans and argues strongly that the adoption of the principles of justice as fairness will not threaten the rights and freedoms to which we have all been accustomed. But indeed, how convincing are these assurances once we realize that ultimately for Rawls:

Our way of life, whatever our particular
circumstances, must always conform to the
principles of justice that are arrived at
independently. Thus the arbitrary features of
plans of life do not affect these principles,
or how the basic structure is to be arranged.
The indeterminacy in the notion of rationality
does not translate itself into legitimate
claims that men can impose on one aqother.
The priority of right prevents this. Iny
emphasis]

Here Rawls lays his cards on the table. Multiplicity and variation of life-plans are to be allowed and individual self-expression encouraged, BUT 
ONLY TO A POINT! They cannot conflict in any way with the pre-established principles of justice, since "the priority of right prevents this." Thus no matter how much Rawls may embellish his theory of the good to include individual aims and desires; no matter how many safeguards he installs in his theory to prevent encroachments on individual self-expression and liberty, once he postulates in any way that right takes precedence over good, then his theory thereby becomes deontological and is consequently subject to all the criticism which the latter doctrine entails (e.g.. that it is unnecessarily dogmatic, that it fails to take into account changing social and envíronmental conditions, that it presupposes a certain unacknowledged psychological view of man, etc.). Perhaps it was Dewey who best articulated the misgivings that many have with regard to a deontological ethics:

Experience shows that the subordination of
human good to an external and formal rule
tends in the direction of harshness and
cruelty. The common saying that justice
should be tempered with mercy is the popular
way of stating recognition of the hard and
ultimately unjust character of setting up a
principle of action which is divorced from all
consideration of human consequences. Justice
as an end in itself is a case of making an
idol out of a means at the expense of the end
which the means serves."

It is, of course, beyond the scope of this paper to discuss exhaustively the comparative merits of a deontological versus a naturalistic ethics. But what is important here from our standpoint is Rawls's claim that in his system the right and good are somehow "congruent" with one another, i.e.. that "justice as fairness" is congruent with the notion of "goodness as rationality." or, more precisely, that "it is rational for those in a well-ordered society to affirm theig sense of justice as regulative of their plan of 1 ife." 9

In other words, it is rational for us to desire justice (the Right) as an end (the Good), hence a "congruence." As this statement indicates, and as we have previously noted, Rawls tries to incorporate as many elements as possible from both deontological (right-oriented) and naturalistic (good-oriented) systems of ethics, such that his theory can be said, as it were, to provide us with the "best of both worlds," the combined advantages of both systems. Yet his 
repeated emphasis on the priority of Right in his theory belies his claim for congruence.

More importantly, is such a congruence even possible given the divergent premises of the two approaches to ethics. Although the good and the right, as Rawls sets them up, may be eminently compatible, it does not follow from this that they are thereby made congruent and are capable of synthesis into a theory of justice.

Can the notions of right and good ever be made congruent, or are they simply mutually exclusive? It appears that once the element of right is allowed into an ethical theory, it must, by definition, take precedence over the good. If right does not take precedence over the good, then right necessarily becomes relative to the good, thus becoming a good itself. That is, if right is relative, and not "absolute," its value must then be relative to some perceived good (that quality by which one right is selected or accepted and another rejected). The latter view is, in fact, held by the naturalists, i.e., that in the course of everyday social and ethical interaction, certain values emerge which themselves are subject to change in accordance with further alterations in those existential situations. It is interesting to note in Part Three of A Theory of Justice that the same arguments Rawls uses in support of such positions as those of individual integrity, the need for the diversity of 1 ife-plans, etc. are often used by the naturalists to support their claim that. there is No overriding principle(s) of right. That is, again, that values emerge in the acting-out of 1 ifeplans and do not exist beforehand in an absolute, deontological fashion.

Thus in the question of right vs. good, epistemology vs. ethics, deontology vs. naturalism, there is, unfortunately, no middle ground. These positions cannot exist coequally since the usual definition of each of these terms excludes the notion of its opposite within itself (in fact, usually as subordinate to itself). Accordingly, the proponents of the Right see good as resulting from the proper adherence to the Right, while the champions of the Good view the right as something which emerges in the pursuit of the Good.

Our arguments along these lines should not be construed as mere Jesuitical hair-splitting of definitions, for they point to a wider problem. As 
long as ethics and justice, in particular, continue to be viewed and defined in terms of these classical philosophical distinctions, those of what James called "intellectualism" (i.e.. right vs. good, is vs. ought, etc; as Dewey often pointed out, to set up an exhaustive dualism presupposes, often wrongly, that the entities are entirely separate to begin with), inconsistencies such as those outlined here with regard to Rawls's theory are bound to appear. The complex psychological, motivational, biological, and cultural patterns woven into the exguisite tapestry that is man and his actions are far too sophisticated to be reduced exclusively to particular concepts such as those of right and good. A proper delineation of justice requires as its necessary propaedeutic an adequate description of man IN his ethical situation, his concrete relationships to himself, to others, and to the world around him. These "existential" phenomena must be dealt with in the manner in which they occur, in actu, and not merely as facts to be grouped under one conceptual heading or another.

Rawls, for his part, does an excellent job on this count, especially in the latter part of his theory. He displays a sound understanding of the nature of social and institutional behavior. He also possesses keen historical insight into the past philosophical attemtpts at theorizing justice and has an uncanny knack of being able to pull the best elements out of competing views on justice, and then to synthesize them into one strong, internally coherent position.

But insofar as Rawls chooses to view justice deontologically, to see Right as the preeminent concern of a well-ordered society and adherence to "rightness" as the preeminent concern of the individual in that society, then A Theory of Justice will be no more than just another attempt, albeit a well-intentioned and thought-out one, at a rationalistic ethics, "condenned" (to classrooms and seminars and not to application to the real problems of humans) for its failure to include the "whole" person, not just the rational part of him/her, in its initial premises.

\section{Southern Illinois University. Carbondale}


NOTES

${ }^{1}$ John Dewey, Theory of the Moral Life, (New York: Holt, Rinehart \& Winston, 1960), p. 89.

2 John Rawls, A Theory of Justice (Cambridge: Belknap Press, 1971), p. 567 .

$3_{\text {R }}$

Raw1s, p. 572 .

${ }^{4}$ Rawls, p. 448 .

${ }^{5}$ Rawls, p. 448 .

6rawls, p. 449.

7 Rawls, p. 449.

${ }^{8}$ Dewey, p. 105.

9 Rawls, p. 567. 